\title{
Is science value-free?
}

SIR - Contrary to the view of Bernard D. Davis (Nature 27 September, p. 294), value judgements are inherent in scientific knowledge and scientific practice. They can be identified most readily when science is applied to problems of the real world such as energy, environment and health. These problems are very complex and scientific information on them is generally far from complete. As a consequence, the scientist inevitably has to make value judgements which involve the selection of data, of scientific procedures for analysing data and of assumptions about unknown variables. Furthermore, in presenting the results of this selection process to peers, to decision-makers or to the public, the scientist has to make selections of definitions and terminology and of the context in which the results are exhibited. (Davis's use of the value-laden phrases "periphery of science", "fashionable", "confusion" and "radical left" should be noted.)

Such value judgements do not occur in random directions. They are part of a science which is performed in a particular social, political and economic context, which includes:

- industrial, bureaucratic, government and military motivation for, and financial support of, most scientific research;

- the limited accessibility, understandability and exploitability of most scientific research to anyone except large organizations with vested interests;

- the effective monopolization of the opportunity to do scientific research by full-time professionals;

- the restriction of decision-making about scientific research priorities to a small group of power-holders.

In this context, the value judgements, and therefore science itself, are given a direction or bias, namely that which is selectively useful to elite groups. (See Hilary and Steven Rose (eds) The Political Economy of Science and The Radicalisation of Science; Brian Martin, The Bias of Science; Randall Albury, The Politics of Objectivity.) In many examples - for example the risk of fallout from nuclear weapons tests, electricity generation planning - the public is given the incorrect impression that the issues involved are purely "scientific", "technological" or "economic" in nature, when in reality they rest in part on social, political or ethical judgements (see my article in David Oldroyd (ed.) Science and Ethics, NSW University Press).

Why is the notion that science is "objective" or "value-free" promoted so strongly? I would suggest that an important reason is that science is used widely to legitimize the products and policies of elite groups. My own particular bias is towards a kind of democracy which allows greater public participation in decision-making on social, political and economic issues. By questioning the notion of value-free science, it is my hope that the community will eventually create a new type of science which is more responsive to the needs of the community at large than to the military, big business, elite scientists, bureaucracy and government.

The views expressed in this letter are not necessarily those of any organization with which I am associated.

MARK DIESENDORF

CSIRO Division of Mathematics \&

Statistics,

Canberra ACT 2601,

Australia

\section{Misnomer}

SIR - The article on the prehistory of Amazonian Indians by Robert May (Nature 1 November, p.19) included an inference that bronchial pneumonia (sic) decimated groups of indigenes.

Bronchopneumonia is a disease affecting the terminal airways, giving rise to patchy consolidation of the lung parenchyma. Lobar pneumonia causes consolidation of whole lobes of the lung. Either type may be spread by infection and cause epidemics.

"Bronchial pneumonia" is a popular misnomer with no pathological basis due, I suspect, to mishearing bronchopneumonia. In this case, I suggest the epidemic was due to influenzal bronchopneumonia as in the pandemic following World War I.

Department of Pathology.

University of Leeds,

Leeds LS2 9JT, UK

\section{SAAO telescopes}

SIR - If 156 UK astronomers believe that "continued funding of the South African Astronomical Observatory (SAAO) amounts to acquiescence in apartheid" (Nature 312, 295; 1984), it is probable that many of these UK astronomers will not use SAAO.

The scientific returns on the investment by the Science and Engineering Research Council (SERC) in SAAO probably correlates with the fraction of active UK astronomers who are prepared to use the SAAO telescopes.

The declaration presented to SERC indicates that a significant fraction of active UK astronomers are unlikely to consider using the SAAO telescopes. That surely is a good enough "scientific consideration" for SERC to transfer its meagre astronomy resources to telescopes that all astronomers are prepared to use.

Department of Physics, JOHN BARUCH

University of Leeds,

Leeds LS2 9JT, UK

\section{Down with animal lib}

SIR - Nature is increasingly devoting its pages to leading articles, letters, book reviews, news items and lengthy commentaries (for example, refs 1-6) on animal "rights", "welfare" and "abuse". In 30 issues from 26 April to 15 November 1984, about 14 pages were dedicated to this subject compared with fewer than 7 dealing with human rights from Argentina to the Soviet Union. Matters such as the devastating famine in sub-Saharan Africa, to the relief of which scientists can contribute a great deal, were not even mentioned.

I do not care whether cuddly animals (nobody seems to care about prokaryotes, ectothermes and protozoa) are abused, killed, eaten, mistreated or otherwise molested for pleasure, profit, the advancement of science or the American way, within or without laboratories, and I wish Nature, if not to adopt my point of view, at least to focus more on the species to which presumably most of its readers and, more importantly, subscribers belong.

DAN GRAUR

\section{Center of Demographic and}

Population Genetics,

University of Texas,

Health Science Center,

Houston, Texas 77225, USA

1. Beardsley T. Nature 309, 8 (1984).

. Cosslett V.E. Nature 309, 186 (1984)

3. Goodwin L.G. Nature 309, 729 (1984).

4. Stevens C. Nature 312, 295-297 (1984).

5. Remfry J. Nature 312, 191 (1984).

6. Editorial. Nature 312,2(1984).

\section{India's diversity}

SIR - I take strong exception to your reference to India as a "huge country, which is in reality six or seven countries" (Nature 8 November, p. 87), a remark suitable for extremist newspapers not periodicals such as Nature. It is difficult to judge if a journal which I so assiduously read was indulging in provocative journalism apparently legitimizing secessionist attitudes or simply exhibiting ignorance. Extending your view, this very island nation would thus represent an artificial conglomeration of essentially disparate peoples of at least four countries or perhaps three discounting a united Ireland. India was strong enough to withstand the loss of Mahatma Gandhi during those critical few years after independence and will weather the recent loss of Indira Gandhi with reinforced national unity amid a proud exhibition of cultural diversity.

Laboratory of Molecular Biology.

Medical Research Council Centre,

University Medical School,

Hills Road, Cambridge CB2 $2 Q H$, UK

The phrase objected to was not intended in the sense assumed but as a reference to the cultural diversity of India - Editor, Nature. 